\title{
TÉCNICAS DE EJECUCIÓN DE LA GUITARRA FLAMENCA: HISTORIA, DESARROLLO, APORTE Y MECANISMOS
}

\author{
Ejecution techniques of the flamenco guitar: \\ History, development, contribution and mechanisms
}

Ramonet Rodríguez Castillo*

\section{RESUMEN}

Este artículo elabora una breve reseña histórica de la guitarra flamenca. Se acerca a sus más destacados guitarristas, nos habla sobre su evolución y su desarrollo técnico. Además, se centra en los principales mecanismos técnicos, cada uno ejemplificado con su respectiva partitura para una mejor comprensión, escudriñando dentro de ellos para revelar sus cimientos, entender sus cualidades y descubrir sus secretos.

Palabras clave: Flamenco, guitarra, música, técnicas de flamenco.

\begin{abstract}
This article develops a brief historical review of the flamenco guitar. It approaches its most outstanding guitarrists, tells us about its evolution and technical development. Furthermore, it focuses on the main technical mechanisms, each one exemplified by its corresponding score for a better understanding, by scrutinizing them in order to reveal their foundations, understand their qualities, and discover their secrets. Key Words: Flamenco, guitar, music, flamenco techniques.
\end{abstract}

Universidad de Costa Rica, Guitarrista. Docente Escuela de Artes Musicales. Máster en Artes. Costa Rica Correo electrónico: ramonet.rodriguez@ucr.ac.cr

Recepción: 29/4/2014. Aceptación: .20/7/2015 


\section{Desarrollo técnico}

Realmente es difícil precisar el origen de la técnica de ejecución en los instrumentos musicales, sin embargo en el tema propuesto, es decir, la guitarra flamenca, se intentará una aproximación.

Norberto Torres Cortés expone tres sistemas de acercamiento sobre lo que sucedía en el desarrollo de la técnica de la guitarra flamenca a principios del siglo XX. El método de Marín, los registros sonoros y la iconografía. (1997: p. 81).

\subsection{Sistemas de Acercamiento}

\subsubsection{Método de Marín}

El primer método de guitarra flamenca en la historia de la música andaluza es el de Rafael Marín (Sevilla, 1862-Madrid, ...) publicado en 1902, cuyo título es: Método de Guitarra por Música y Cifra. Aires Andaluces. En este método Marín habla de la ausencia de una escuela de manos en el género andaluz. Comenta que cada guitarrista coloca las manos como ha podido o ha sabido y que es necesario tener una adecuada colocación de las manos y conocer los mecanismos de la guitarra. Se sabe por este método que la técnica de la época era muy básica y se limitaba a escalas con el pulgar, rasgueos en la mano derecha, pocos acordes en la mano izquierda y en muy pocas ocasiones la utilización de un trémolo de dos dedos y escasas fórmulas de arpegio.

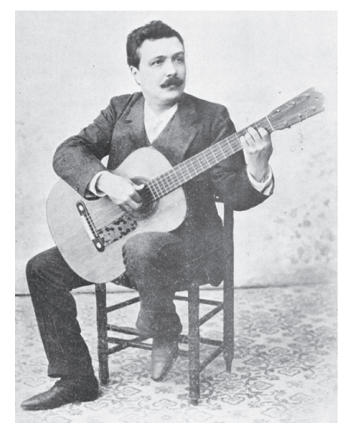

FIGURA 1

Rafael Marín. Método de Guitarra. 1902.

\subsubsection{Registros sonoros}

Los registros sonoros que se han recopilado en cilindros desde 1890 a 1905 y los primeros discos de 1920, permiten apreciar la guitarra acompañante del cante ${ }^{1}$. Estas grabaciones presentan algunas falsetas ${ }^{2}$ cortas que muestran el uso del pulgar, picados cortos, arpegios ascendentes simples y trémolos de dos o tres notas.

\subsubsection{Iconografía}

Existen dibujos, litografías, acuarelas y fotografías de guitarristas de principios del siglo XIX hasta nuestros días, que permiten apreciar posturas y colocación de las manos en una evolución diacrónica de la técnica. Muestran la tradicional posición vertical del instrumento. También, la colocación de los dedos pulgar, medio y anular, apoyados en la tapa mientras el índice rasguea hacia arriba en las cuatro primeras cuerdas. Se puede apreciar la mano derecha cerca del puente.

Javier Molina (Cádiz, 1868-1956), colocaba la guitarra de manera casi vertical.

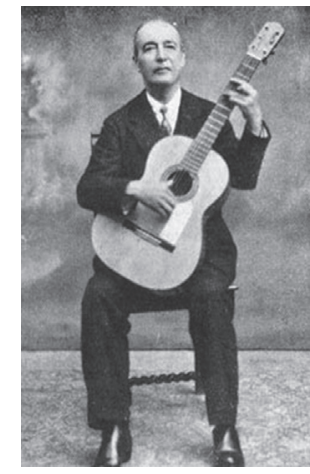

FIGURA 2

Javier Molina. En: https://www.google.com/

Una foto de Manolo de Huelva (Huelva, 1898-Sevilla, 1976), muestra el cambio de colocación del instrumento, hacia una posición más horizontal, como si se tratara de un guitarrista clásico.

Una foto de Rafael Marín muestra su propuesta mixta: posición clásica del instrumento y de las manos, pero sin el taburete (descansa 
pie) ya que utiliza un apoyo de la misma silla para colocar el pie.

Hay guitarristas, como Ramón Montoya (Madrid, 1880-1949), que colocan las manos como guitarristas clásicos, pero descansando la guitarra en la pierna derecha. (El guitarrista clásico apoya o descansa la guitarra en la pierna izquierda).

El Niño Ricardo (Sevilla, 1904-1972) tiene una colocación de las manos como clásico pero descansa la guitarra en la pierna derecha.

Paco de Lucía (Cádiz, 1947-2014) cruza la pierna derecha en donde coloca la guitarra y utiliza una posición horizontal del instrumento.

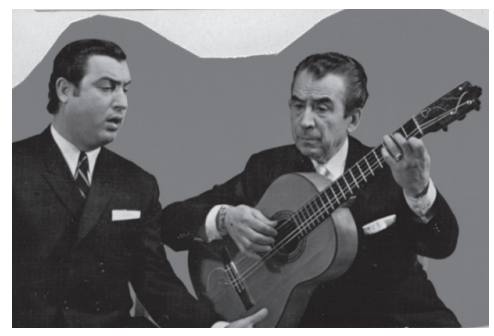

FIGURA 3

Manolo Mairena y Niño Ricardo. En: https://www.google.com/

Es importante señalar que no se cuenta con datos sobre la guitarra flamenca como tal, sino hasta finales del siglo XVIII. La guitarra había estado al servicio del cante o subordinada al baile con recursos técnicos muy reducidos "tocar a lo barbero", es decir, con un sencillo rasgueo al que seguía un simple punteado. A finales del siglo XIX y principios del XX la guitarra flamenca recibe influencias importantes de la guitarra clásica al coincidir en los cafés cantantes $^{3} \mathrm{o}$ en espacios similares.

Los guitarristas flamencos tratan de emular a figuras importantes de la guitarra clásica como Julián Arcas (1832-1882), Francisco Tárrega (1852-1909) y Miguel Llobet (1878-1938).

Miguel Llobet y especialmente Julián Arcas cultivaban además el arte flamenco, y muchas de sus composiciones con gran desarrollo en sus falsetas, requerían de gran destreza técnica. Numerosos guitarristas de flamenco en busca de prestigio aprendían falsetas de Arcas lo que les obligaba a desarrollar una mejor técnica. Es así como a finales del XIX y principios del XX se da la denominada escuela clásico-flamenca.

Otros guitarristas clásicos de esta época que incorporaron piezas flamencas en sus repertorios eran: Antonio Sánchez, Bernardo Troncoso, José Pérez, Antonio Marín y José Toboso.

\subsection{Perfeccionamiento técnico}

A mediados del siglo XIX la guitarra flamenca era relacionada con el rasgueo, la sencillez y pocos recursos técnicos. Estaba subordinada al cante, al baile y arrastraba una gran pobreza musical. De hecho, los primeros guitarristas de flamenco eran cantaores ${ }^{4}$ que se acompañaban a sí mismos, debido a que el guitarrista independiente dedicado al flamenco era casi inexistente. El guitarrista más antiguo que se conoce es Francisco Rodríguez Murciano (Granada, 1795-1848).

Ejemplos de cantaores que se acompañaban a sí mismos son: EL Planeta, El Tío Abejorro y Juan Breva. Sin embargo, a finales del siglo, los guitarristas se preocuparon por desarrollar recursos técnicos, enriquecer musicalmente sus falsetas y dirigirse hacia la guitarra flamenca solista. Esta tarea la realizaron de la mano de la guitarra clásica y con el afán no sólo de superarse musicalmente y poder ejecutar pasajes de gran calidad, dificultad, desarrollo y belleza, sino también de adquirir prestigio y alejarse de esa posición de menosprecio y pobreza técnico-musical.

De la escuela clásica, sólida en técnica y con un vasto repertorio de gran calidad, el flamenco fue tomando algunas de sus características:

\subsubsection{Postura (colocación de la guitarra)}

A partir de los inicios del siglo $\mathrm{XX}$ se da un abandono de la colocación casi vertical 
del instrumento, que evidentemente dejó de ser cómoda una vez que los pasajes a ejecutar se hacían más complejos. Algunos guitarristas comenzaron a reposar la guitarra sobre la pierna izquierda y a utilizar banquillos para colocar el pie izquierdo; incluso algunos tocaban con la mano derecha sobre la boca del instrumento, alejándose de la costumbre de tocar cerca del puente, con lo que lograron un sonido más dulce.

\subsubsection{Técnicas}

Se enriquecieron los arpegios y utilizaron diversas fórmulas. Anteriormente eran muy sencillos: pulgar e índice o pulgar e índice y medio ascendentes. Sin embargo, a partir de entonces se comienzan a trabajar también los descendentes.

Se utilizó el picado (escalas) con los dedos índice y medio, lo que permitió una mayor velocidad en su ejecución. Las escalas se tocaban con el pulgar y es evidente que un solo dedo tiene muchas limitaciones para hacer una escala rápida, a no ser que se hicieran ligadas. Javier Molina y Ramón Montoya, son quienes tienen el mérito de haber incorporado esta técnica al flamenco. Al respecto comenta Blas Vega (1970: p. 70): "Ramón Montoya empezó a desarrollar el picado como un nuevo ejercicio, en un alarde de espectacularidad, iniciando así el virtuosismo flamenco".

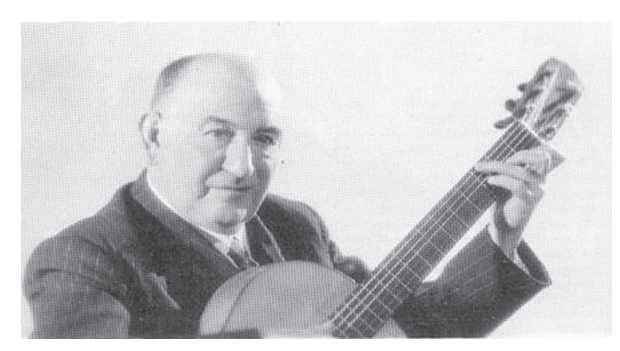

FIGURA 4

Ramón Montoya. En: https://www.google.com/

Es interesante mencionar que esta técnica la utilizó Ramón Montoya en sus actuaciones en el Café del Gato. El picado era mal percibido por los cantaores ya que su uso les quitaba inspiración y protagonismo. El Niño de Cabra, cantaor, en una ocasión dejó solo a Montoya, saliéndose del escenario molesto por el uso que éste hacía del picado.

Sobre Montoya comenta Blas Vega (1970: p. 72):

En la guitarrería de Santos, paraban guitarristas de la escuela clásica y allí vio Montoya al guitarrista más notable de aquella época, Miguel Llobet, cuyas manos producían unos sonidos de una desgarradora belleza y él supo adaptar esta técnica derivada de la escuela de Francisco Tárrega a las necesidades específicas del toque flamenco.

Como se mencionó anteriormente, a finales del siglo XIX y principios del XX, los guitarristas flamencos se iban enriqueciendo con el acercamiento de guitarristas clásicos, pero antes de este acercamiento era muy escasa la utilización melódica en las falsetas. El uso del picado con índice y medio ayudó a ese desarrollo. Además, hubo una mayor preocupación por la calidad del sonido. La influencia de la escuela de Tárrega se hace sentir en la incorporación del trémolo en el flamenco. Ya no sólo vemos el trémolo de dos notas, sino también de tres y hasta de cuatro notas. Asimismo, el guitarrista flamenco comenzó a utilizar el pulgar apoyado con uña a modo de plectro o púa (de allí el nombre de alzapúa) lo que le permitió no sólo hacer escalas rápidas sino también producir determinados efectos sonoros. Rafael Marín señala al respecto en su método de flamenco (1902: p.8):

Las escalas en este género se suelen usar bastante,
pero muy diferente a como las usa el que sólo se
ha dedicado al género serio; éste las haría con
sus dedos correspondientes (índice-medio), y el
flamenco las hace con el pulgar; ahora bien: en
esto tengo que advertir que los efectos que se le
sacan a este dedo una vez bien amaestrado son
incomprensibles.

Entrado ya el siglo XX, vemos como los guitarristas flamencos utilizan cada vez más mecanismos técnicos y elaboran un mayor desarrollo musical hasta alcanzar el presente progreso. 


\section{Guitarristas}

Nos encontramos con Paco de Lucena (Córdoba, 1859-1898), considerado un artífice en la revolución de la guitarra flamenca, y a Javier Molina que enriqueció la guitarra desarrollando toques 5 gitanos.

Con Ramón Montoya la guitarra flamenca adquirió un nuevo rango. Montoya profundizó en la técnica y en el desarrollo de la temática musical. Es fuente de donde beben no sólo los de su época, sino también los de épocas posteriores y además fue uno de los primeros guitarristas en ejecutar el instrumento como solista.

Manolo de Huelva era considerado como uno de los más originales guitarristas de flamenco de mediados del siglo XX. Andrés Segovia se refería a él como un músico de toque sencillo, pero muy flamenco, emotivo y expresivo.

De Morón, el máximo representante fue Diego el del Gastor (Málaga,1908-1973) y de Granada, fueron Juan Carmona Habichuela, Manuel Cano (Granada,1926-1990), Juan Maya y Paco Cortés. Una figura fundamental en la historia de la guitarra flamenca fue Manuel Serrapí, conocido como Niño Ricardo. Integró las cualidades de Montoya, Javier Molina y Manolo de Huelva y proporcionó muchos elementos del toque actual. Por su técnica y sonido influenció a gran cantidad de guitarristas. Paco de Lucía comentaba (Ángel Caballero, 1993: p. 43):

Ricardo fue el maestro de nuestra generación, de Sanlúcar, de Serranito, de todos nosotros. Era el guitarrista que en esa época representaba el no va más, el Papa.

Después del Niño Ricardo, apareció una figura aún más influyente, Agustín Castellón Campos (Pamplona, 1912-1990), conocido como Sabicas, quien hizo una revolución en la técnica: picados en los bordones ${ }^{6}$, arpegios en todas las cuerdas, alzapúa, etc.

La generación posterior a Sabicas, es la que más revolución musical ha provocado, ellos son: Paco de Lucía (Francisco Sánchez, 1947-2014), Serranito (Víctor Monge, 1942-) y Manolo Sanlúcar (Manuel Muñoz, 1943-).
Han sido ellos quienes han incorporado al flamenco: orquestas sinfónicas, tríos, cuartetos de guitarras e instrumentos novedosos para el flamenco como el cajón peruano, la cítara, la batería, el contrabajo o bajo eléctrico, etc. Además, han enriquecido la armonía en busca de nuevas sonoridades, y técnica al dotar al flamenco de gran virtuosismo. Son músicos conscientes de la importancia de evolucionar, manteniendo sin embargo, un gran respeto por las raíces flamencas.

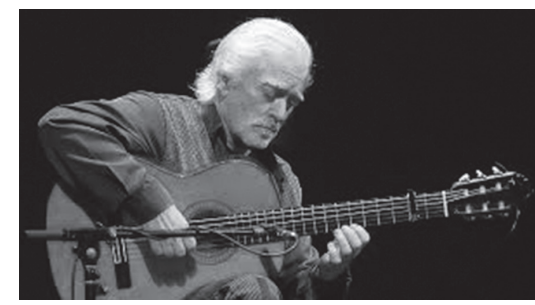

FIGURA 5

Manolo Sanlúcar. En: https://www.google.com/

Si nos remontamos a finales del siglo XIX, observamos que la técnica de la guitarra flamenca era muy sencilla, sin embargo manejaba ya elementos importantes como el rasgueo. De hecho, Rafael Marín en su método de 1902 describe 6 tipos de rasgueos: El graneado, el seco, el chorlitazo, el doble, el golpe y el chorlitazo doble.

Es muy difícil precisar el origen de los rasgueos. Quizá la necesidad de que la guitarra sonara lo suficientemente fuerte como para poder acompañar al cante o al baile. En todo caso el desarrollo del rasgueo es una de las características más importantes del aporte técnico de la guitarra flamenca.

Cabe destacar el hecho de que al guitarrista flamenco no le preocupara una estética determinada de sonido, es decir, una calidad sonora, como al guitarrista clásico (sonido redondo, sin ruidos, con proyección, con nitidez, claridad y matices) y este hecho, sumado a las características musicales del flamenco, le permitió explorar caminos vedados para los guitarristas clásicos. El no estar sujeto 
a una determinada calidad de sonido le abre la posibilidad de experimentar maneras y formas de ejecución diferentes a la guitarra clásica; tal es el caso del alzapúa.

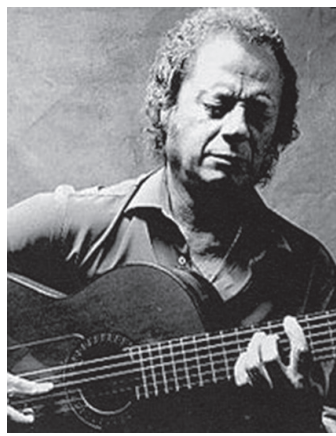

FIGURA 6

Serranito. En: https://www.google.com/

Actualmente el flamenco cuenta con una generación de guitarristas de extraordinaria calidad que se han preocupado por aprender a leer música, a relacionarse con concertistas clásicos, con músicos de jazz, de folklore, etc. Tratan de innovar y aportar elementos que hacen del flamenco un arte vivo y en constante cambio. Ejemplo de ello son los guitarristas Vicente Amigo, Rafael Riqueni, Tomatito, Gerardo Núñez, Óscar Herrero, José Antonio Rodríguez, Chicuelo, Rafael Cañizares, Rafael Andujar, Niño de Pura, Manolo Franco, Pedro Sierra, Niño Josele, Jesús del Rosario y Antonio Rey entre muchos otros.

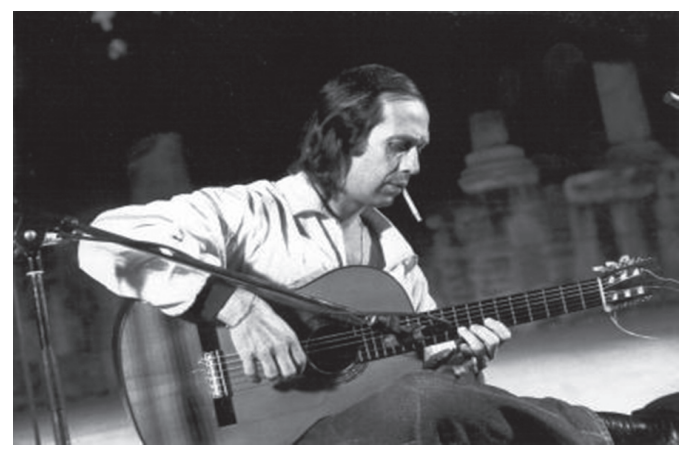

FIGURA 7

Paco de Lucía. En: https://www.google.com/

\section{Mecanismos técnicos de la guitarra flamenca}

Las distintas manifestaciones de música $\mathrm{y}$ arte popular han desarrollado mecanismos técnicos e instrumentales que les ha permitido expresarse; siendo la expresión misma el centro de atención en el que confluyen las inquietudes, necesidades y deseos que el artista pone de manifiesto con su creación. En una persistente búsqueda de medios que le consientan prorrumpir su arte, el artista de arte popular va descubriendo mecanismos técnicos únicos, exóticos, eficaces y no tradicionales, quizás por carecer de un prejuicio estético que le limite a explorar nuevos rumbos. Gracias a muchas de las manifestaciones de música popular, contamos con medios técnicos instrumentales muy interesantes, que surgieron por esa necesidad de expresión y que jamás hubieran florecido en otro medio artístico.

Debido a mi trabajo de investigación realizado en España en el año 1994 sobre las técnicas de ejecución y los estilos del flamenco, pude recopilar una serie de elementos técnicos que desarrollo en este artículo. Estos mecanismos los aprendí directamente de manos de guitarristas flamencos. Muy pocos mecanismos los comparte la guitarra clásica y además con determinadas variantes.

Asimismo, me parece extraordinario el aporte que dichas técnicas pueden ofrecer en el desarrollo de habilidades y grupos musculares, así como su aplicación en obras de guitarra clásica cuyo origen compositivo deriven del flamenco.

\subsection{Técnicas flamencas a exponer y definir}

$\begin{array}{ll}\text { - Rasgueo } & \text { - Arpegio } \\ \text { - Alzapúa } & \text { - Digitaciones de Mano } \\ & \begin{array}{l}\text { Izquierda } \\ \text { - Truce de dedos en mano } \\ \text { izquierda }\end{array} \\ & \\ \text { - Golpe } & \\ \text { - Picado } & \\ \text { - Ligados } & \text { - Movimientos de pulgar }\end{array}$


TABLA 1

Nomenclatura utilizada para los ejemplos

Abreviaturas que indican los dedos de la mano derecha:

$$
\begin{aligned}
& \mathrm{p}=\text { pulgar } \\
& \mathrm{i}=\text { índice } \\
& \mathrm{m}=\text { medio } \\
& \mathrm{a}=\text { anular } \\
& \mathrm{e}=\text { meñique }
\end{aligned}
$$

Abreviaturas que indican los dedos de la mano izquierda:

$$
\begin{aligned}
& 1=\text { índice } \\
& 2=\text { medio } \\
& 3=\text { anular } \\
& 4=\text { meñique }
\end{aligned}
$$

Rasg $=$ rasgueando las cuerdas $\mathrm{X}=$ golpe en la caja de la guitarra $0=$ cuerda al aire

\subsubsection{Rasgueo}

Es uno de los elementos técnicos más importantes y variados. Consiste en rozar las cuerdas de manera rápida con los dedos de la mano derecha (con movimientos en algunas ocasiones en forma de abanico) produciendo un sonido continuo en las cuerdas, subiendo de primas a bordones o viceversa, con muchas posibilidades de combinación de dedos que le van a dar a cada rasgueo una característica sonora. El rasgueo abarcará un determinado número de cuerdas dependiendo de la armonía.

Con él logramos ejercitar los músculos extensores de la mano derecha, es decir, los músculos que provocan el movimiento de los dedos hacia afuera, alejándolos de la palma de la mano. El ejercitar estos músculos permite desarrollar más fuerza, control del movimiento de la mano y mayor resistencia.

Cada vez que un músculo se contrae para producir un movimiento, va a necesitar un grado relativo de contracción, tanto para dirigir el movimiento o posicionamiento, como para regresar a su posición original; de esta manera, para producir un movimiento de flexión, por ejemplo, un grupo muscular de extensión va a facilitar junto a otros grupos de músculos, el regreso a la posición original, de allí la importancia de que un grupo muscular antagónico se ejercite para mantener un adecuado balance entre los movimientos. A continuación se ilustran diferentes rasgueos con múltiples combinaciones de dedos: 


\subsubsection{Rasgueos derivados del graneado}

a)

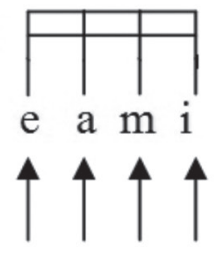

d)

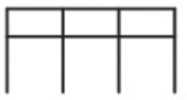

a $\mathrm{m}$ i $\mathrm{i}$

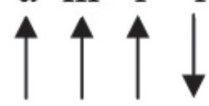

b)

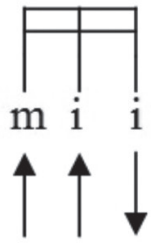

e)

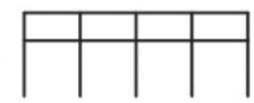

e a $\mathrm{m}$ i $\mathrm{i}$

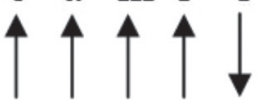

EJEMPLO 1. Grupo de rasgueos. c)

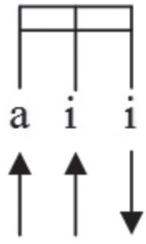

d)

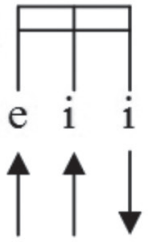

f)

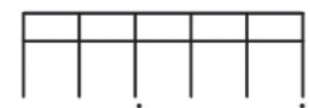

a $\mathrm{m}$ i a $\mathrm{m}$ i

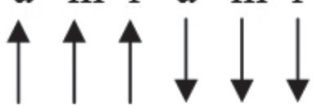

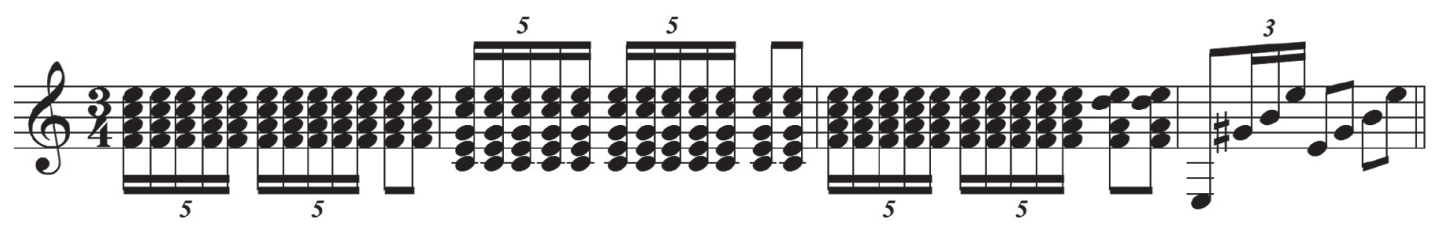

EJEMPLO 2. Utilización del rasgueo f).

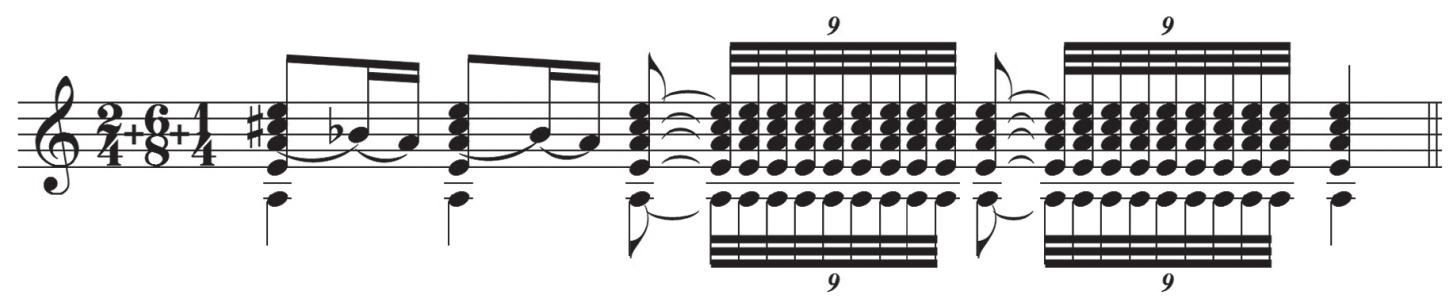

EJEMPLO 3. Utilización del rasgueo f) y a) consecutivamente. 


\subsubsection{Rasgueo redondo}

El pulgar hacia arriba en contraposición al movimiento de los restantes dedos, con un pequeño giro de muñeca.

a)

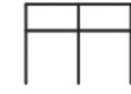

$\mathrm{p}^{\mathrm{m}} \mathrm{i} \quad \mathrm{p} \quad \mathrm{m} i$

c)

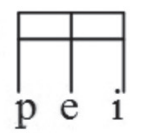

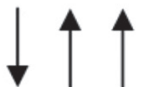
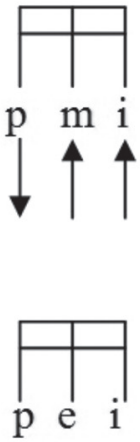

e)

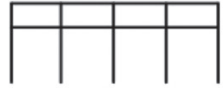

b)
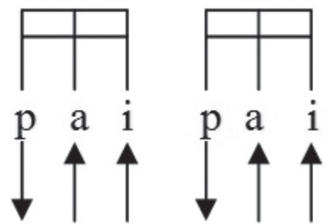

d)

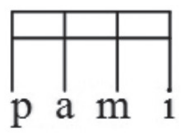

$\sqrt{1} \uparrow \hat{4}$
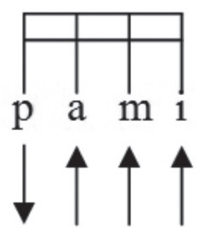
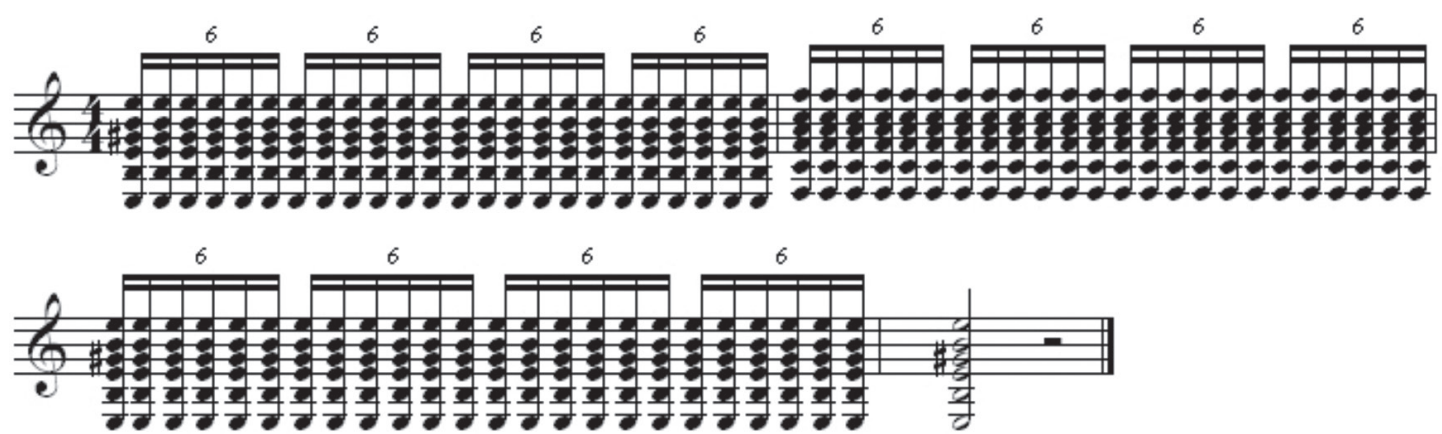

EJEMPLO 5. Utilización del rasgueo a). 


\subsubsection{Rasgueo de bola}

Utiliza solamente dos dedos (pulgar alternado con otro dedo).

a)

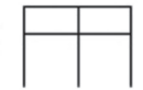

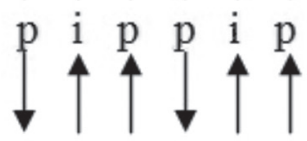

c)

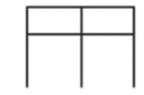

$\mathrm{p}$ a $\quad \mathrm{p} \quad \mathrm{p}$ a $\mathrm{p}$

$\downarrow \uparrow \uparrow \downarrow \uparrow \uparrow$

e)

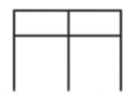

i $p$ i $\quad$ i $p$ p

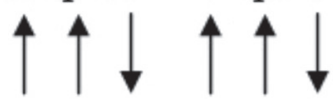

b)

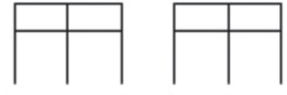

$\mathrm{p}_{\downarrow}^{\mathrm{m}} \mathrm{p} p \mathrm{~m}$

d)
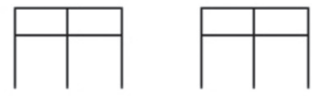

$\mathrm{p}$ e $\mathrm{p} \quad \mathrm{p}$ e $\mathrm{p}$

$\downarrow \uparrow \uparrow \downarrow \uparrow \uparrow$

f)
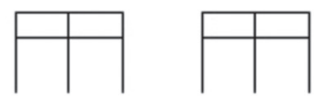

$\mathrm{m} \mathrm{p} \mathrm{m} \mathrm{m} \mathrm{p} \mathrm{m}$

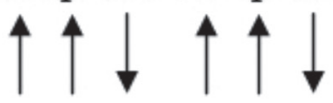

EJEMPLO 6. Grupo de rasgueos.

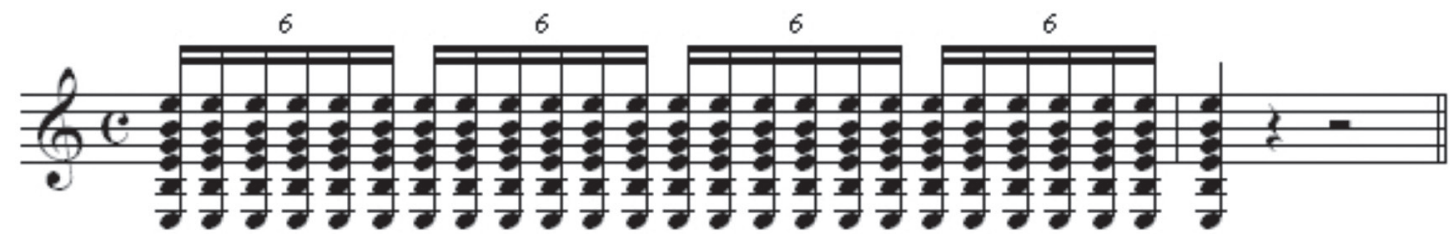

EJEMPLO 7. Utilización del rasgueo b). 


\subsubsection{Alzapúa}

Es una técnica propia del dedo pulgar de la mano derecha en donde éste funciona como una púa o plectro, pulsando una, dos o más cuerdas para conseguir motivos rítmicos de cierta velocidad, pulsando hacia abajo y hacia arriba, especialmente en bordones, logrando de esta manera un efecto sonoro muy particular.

Existen ocho músculos que participan del movimiento del pulgar que le otorgan importantes cualidades de fuerza y sutileza. Es, de hecho, el dedo más hábil y al cual se le pueden encargar tareas de ejecución que serían muy difíciles para otros dedos.

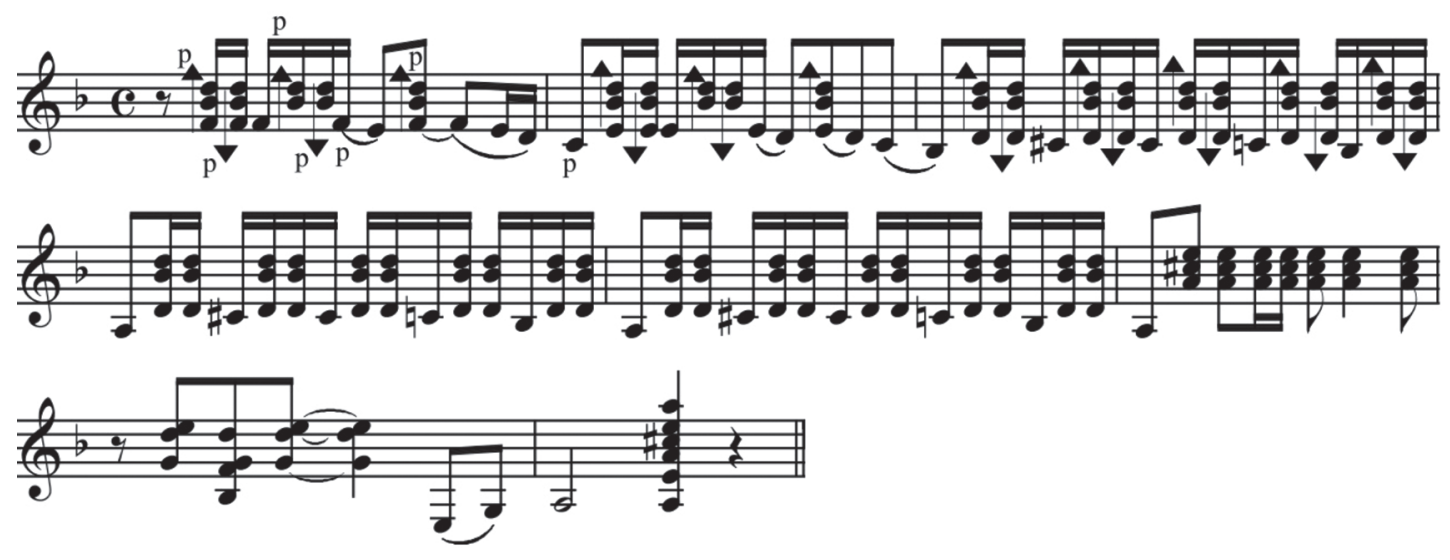

EJEMPLO 8. Alzapúa en Tango.
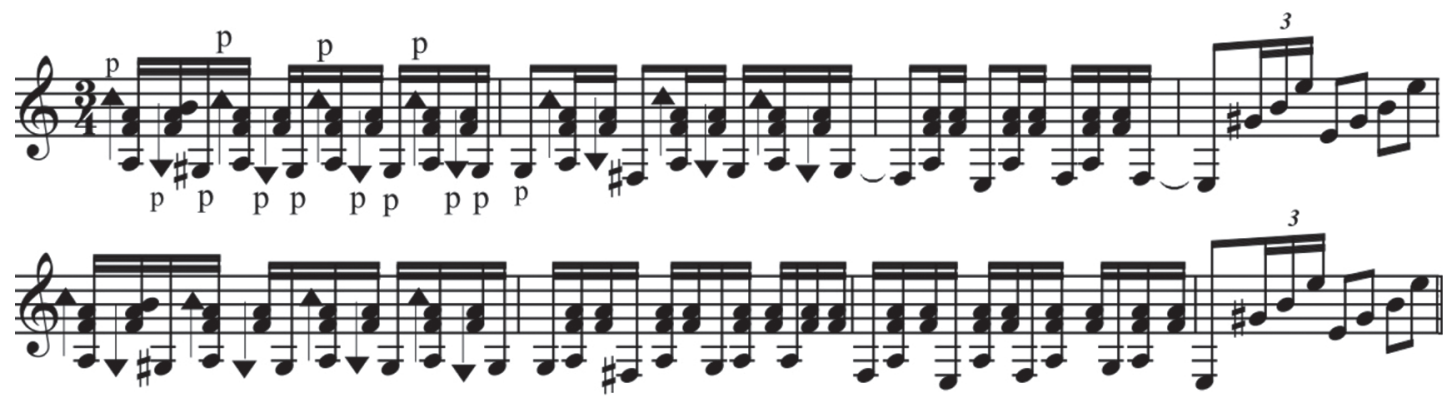

EJEMPLO 9. Alzapúa. 


\subsubsection{Trémolo}

Es la reiteración de notas, más o menos rápida, en una misma cuerda. Se toca un bajo, más la reiteración de una nota. Generalmente en la guitarra clásica se usa el ataque del bajo con el pulgar, más la reiteración de tres notas en una misma cuerda que se realiza con los dedos anular, medio e índice. En la guitarra flamenca se usa el ataque del bajo con el pulgar, más la reiteración de cuatro notas en una misma cuerda, que se realiza con los dedos índice, anular, medio e índice nuevamente.

El trémolo es un gran ejemplo de que ambas guitarras, la clásica y la flamenca pueden complementarse y compartir técnicas.

Para perfeccionar la fórmula del trémolo clásico: pami, recurrimos a estudiarlo lentamente, a utilizar un pañuelo que cubra la vibración de las cuerdas para escuchar una sonoridad más percutida que nos ayude a clarificar la calidad del trémolo, etc. Sin embargo, el estudiar el trémolo flamenco nos proporciona una gran ayuda en el desenvolvimiento del trémolo clásico, primero por la posición típica de la mano en el flamenco que permite que los dedos se coloquen de manera longitudinal con respecto a la cuerda, como si éstos tuvieran un mismo tamaño, lo que facilita su ejecución, y segundo, porque la fórmula flamenca: $\mathrm{p}$ i a $\mathrm{m}$ i, utiliza un dedo más que la clásica, lo que obliga a un mayor esfuerzo para realizar el trémolo. Como consecuencia, su estudio reiterado facilita posteriormente la ejecución de un trémolo más sencillo en número de notas.
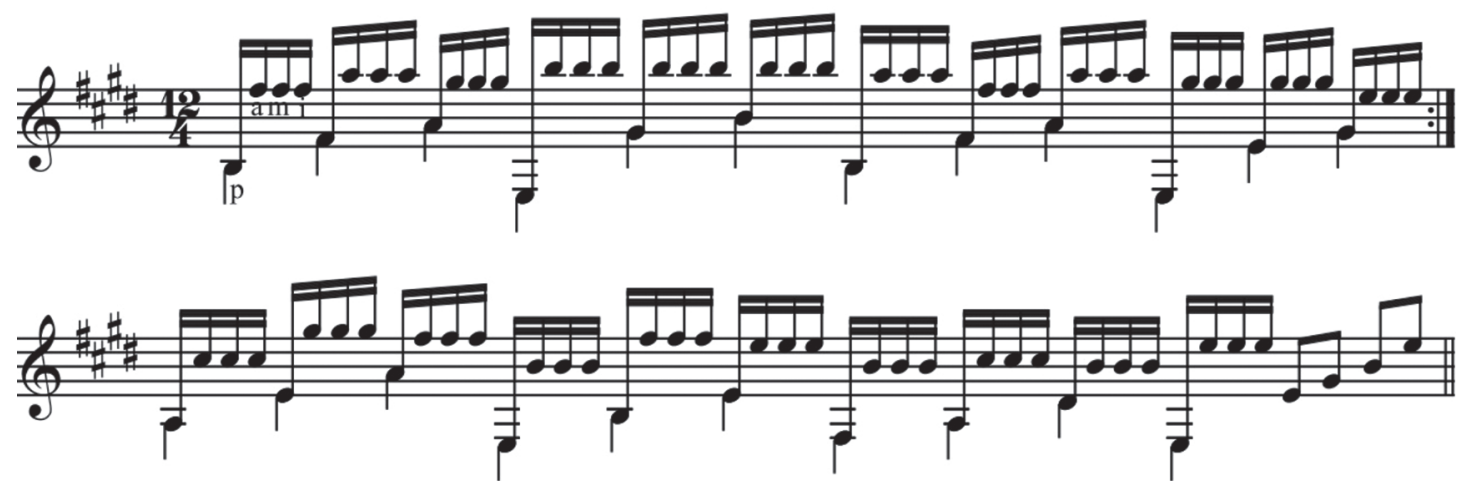

EJEMPLO 10. Trémolo clásico.
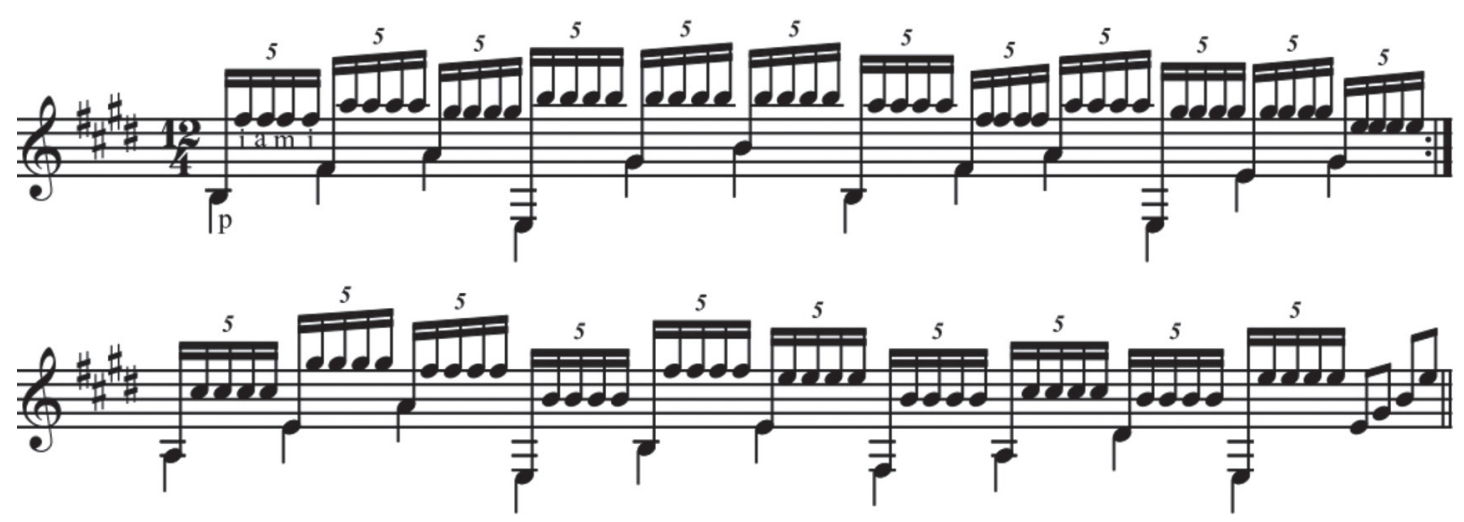

EJEMPLO 11. Trémolo flamenco. 


\subsubsection{Golpe}

Consiste en la acción y efecto de golpear la tapa armónica de la guitarra con la uña o la yema de los dedos de la mano derecha. En el flamenco se desarrolla la ejecución de percusión de manera simultánea o sucesiva a la realización de diferentes acordes, notas, ritmos, rasgueos, alzapúas, etc. Este efecto se utiliza normalmente para apoyar los acentos de determinados toques.

Es importante desarrollar destrezas en este sentido ya que encontramos numerosos ejemplos en la guitarra clásica en donde el elemento de percusión es incorporado como parte vital en la composición. El golpe se puede realizar con el pulgar, el índice, el medio o el anular. En algunos momentos también se pueden utilizar el medio y el anular de manera conjunta.

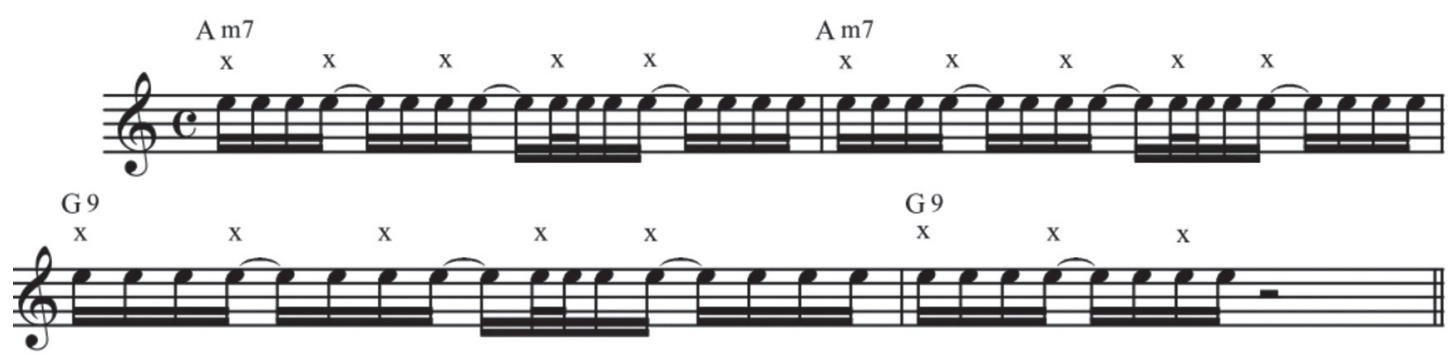

EJEMPLO 12. Golpe de tapa con ritmo de Rumba.
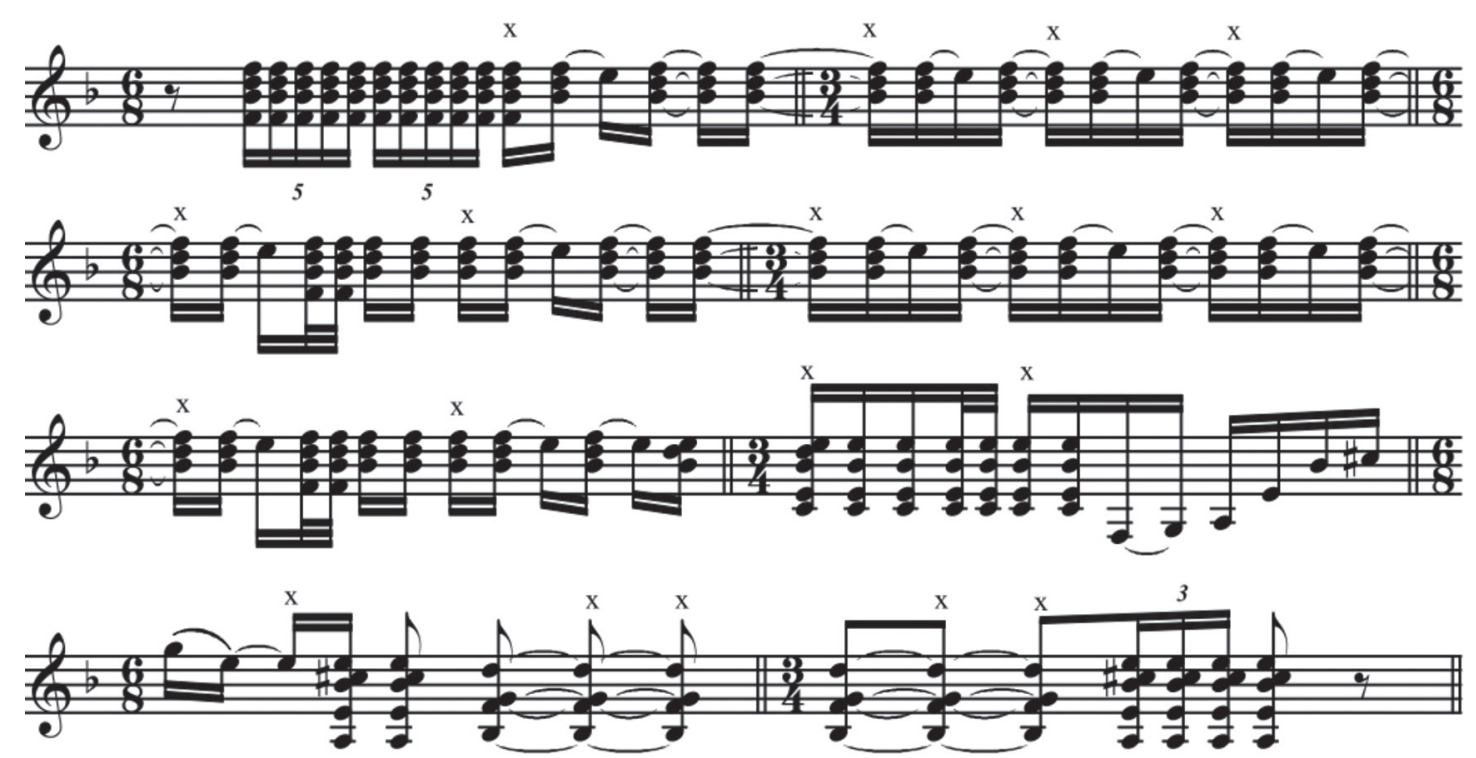

EJEMPLO 13. Golpe de tapa en Bulería. 


\subsubsection{Picado}

Conocido también como punteado, es el uso alternado del índice y medio para realizar especialmente escalas o ejecutar melodías. No obstante, hay picados que se pueden realizar con la combinación de otros dedos.

Es una técnica muy utilizada y propia de la guitarra clásica, sin embargo en el flamenco adquiere matices expresivos de gran riqueza debido a la fuerza y rapidez con la que es ejecutada. Quizá la diferencia fundamental está en la forma del ataque. En el flamenco se ejecutan las escalas con los dedos de frente a la cuerda, con mucha fuerza y normalmente con uñas de extensión muy corta. El punto de ataque es generalmente cerca del puente.

En muchas ocasiones se extiende la articulación interfalángica distal, es decir, se extienden las puntas de los dedos para no ofrecer resistencia a la cuerda. Se busca que el ataque vaya dirigido de manera perpendicular a la tapa de la guitarra y que el movimiento de extensión de retorno para el nuevo ataque sea lo más pequeño posible, como si se tratara de un pequeño rebote natural.
Su ejecución se puede realizar ya sea con un movimiento gradual de flexión o extensión del antebrazo o con un movimiento gradual de elevación o descenso del hombro.

Lo interesante de estudiar las escalas de esta forma es que se logra gran velocidad y volumen de sonido, ya que los dedos desarrollan la fuerza necesaria para romper con facilidad la resistencia que la cuerda ejerce sobre ellos. Algunos guitarristas de flamenco usan el picado descendente alternando los dedos índice y medio, por ejemplo, si tocan la primera cuerda con el índice y deben pasar inmediatamente a la segunda cuerda, lo harán con el medio, haciendo una especie de cruce de dedos. Este cruce de dedos lo ejecutan, sin embargo, de manera impecable.

Dos grandes guitarristas que realizan de manera extraordinaria las escalas descendentes alternando dedos son: Paco de Lucía y Manolo Sanlúcar. También hay quien arrastra el dedo índice en la realización de escalas descendentes, de primera a segunda cuerda, o de segunda a tercera, etc. Un ejemplo de ello es el gran guitarrista Pepe Romero.

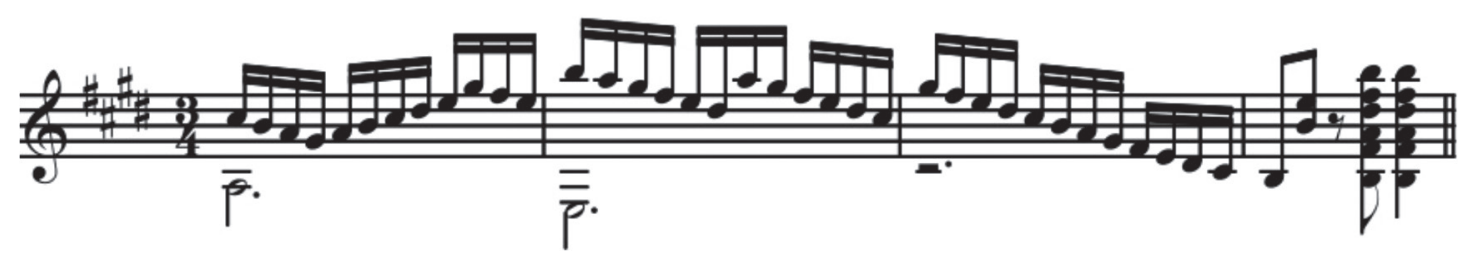

EJEMPLO 14. Escala rápida típica de Alegrías.

\subsubsection{Arpegio}

Es la sucesión más o menos acelerada de los sonidos de un acorde o grupo de notas. En la guitarra se produce al pulsar con los dedos de la mano derecha diferentes cuerdas en forma alternada y sucesiva, existiendo para ello innumerables posibilidades de combinación.
En el flamenco se realizan fórmulas de arpegio no usuales dentro de la guitarra clásica, como por ejemplo, determinada combinación de arpegios con ligados o arpegios con arrastres de algún dedo sobre las cuerdas (como rasgueando). Esto permite un mayor entrenamiento de los dedos para lograr un dominio más eficaz en el arpegio. 

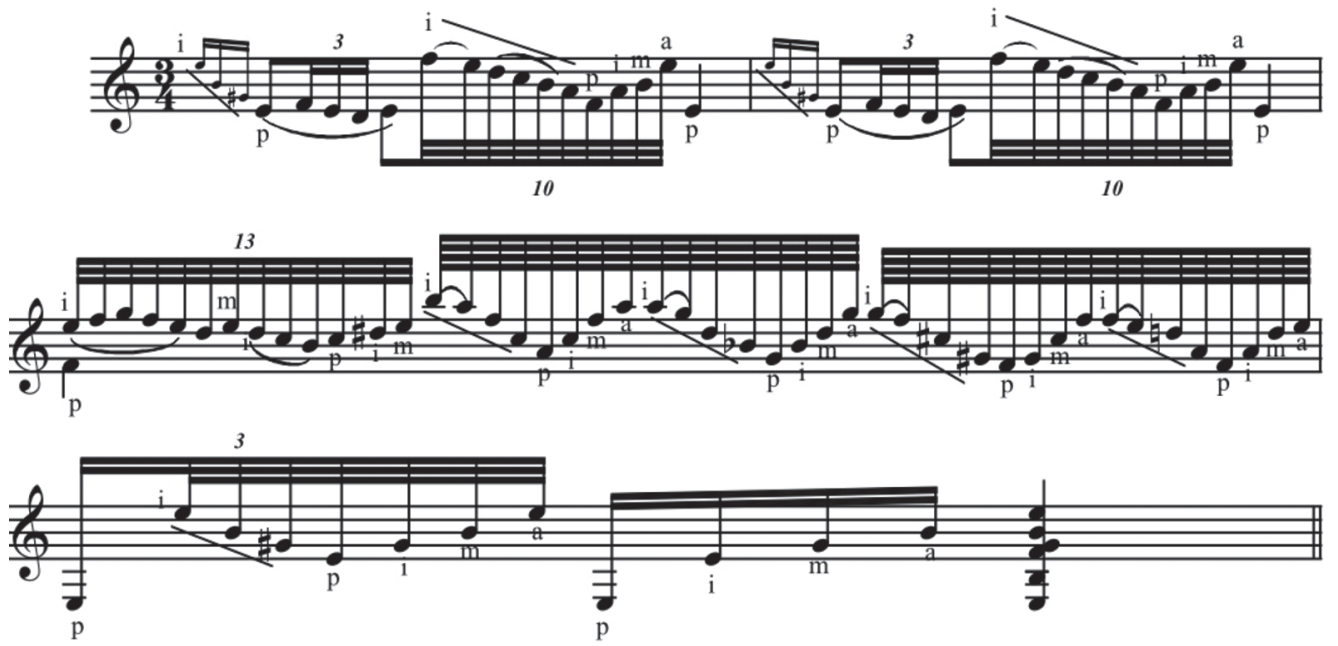

EJEMPLO 15. Arpegio flamenco.

En algunas ocasiones se utiliza un arpegio muy particular en donde el pulgar ataca la misma cuerda que ataca el índice, esta reiteración de la primera nota produce una sonoridad especial. Además, estrecha el ámbito de pulsación de la mano para realizar el arpegio.

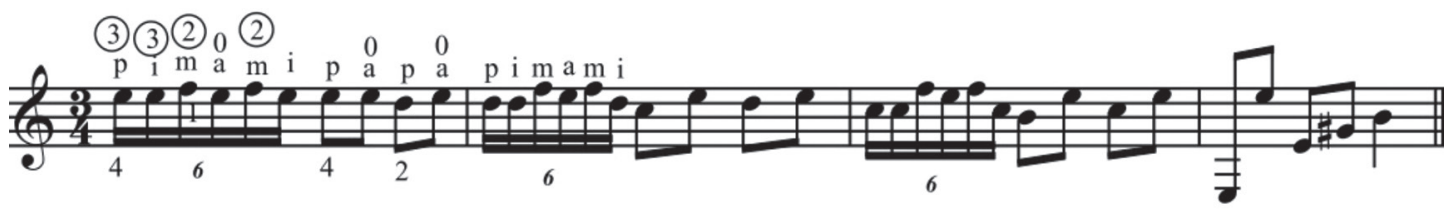

EJEMPLO 16. Arpegio.

\subsubsection{Digitaciones de mano izquierda}

Hay algunos acordes muy utilizados en el flamenco con digitaciones poco frecuentes para la mano izquierda en la guitarra clásica y cuyo dominio nos permite una mayor destreza en el instrumento.

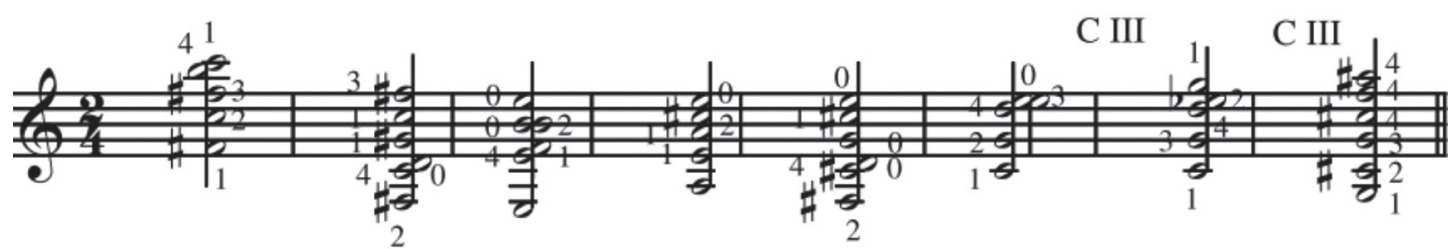

EJEMPLO 17. Acordes usuales en flamenco. 


\subsubsection{Cruce de dedos en mano izquierda}

También existen algunas posiciones con cruce longitudinal de dedos, es decir, por ejemplo, dedos 3 y 4 en un tercer traste, ejecutados de manera simultánea con el dedo 2 en un cuarto traste.

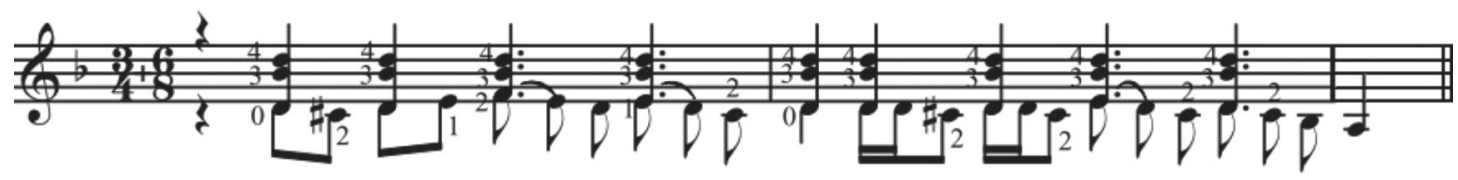

EJEMPLO 18. Posiciones de cruce.

\subsubsection{Ligados}

En la guitarra, el ligado de articulación es el efecto de unir dos o más sonidos que se van produciendo de manera descendente cuando los dedos de la mano izquierda deslizan la cuerda hacia abajo y se desprenden de ella para dar paso a la siguiente nota, o de manera ascendente cuando los dedos de la mano izquierda van majando el traste para producir el sonido únicamente por su ataque, sin la intervención de la mano derecha. La mayor parte de las veces la mano derecha interviene solo en el primer ataque del grupo ligado. Con dicha articulación no se separan las notas sino que se les da continuidad.

En el flamenco se pueden encontrar ligados utilizados de diversas maneras. Es muy frecuente una forma especial en la que se ligan consecutivamente grupos formados por numerosas notas y se realizan con la mano izquierda sola, sin necesidad de pulsar con la mano derecha, muy común en el toque flamenco de Taranta.
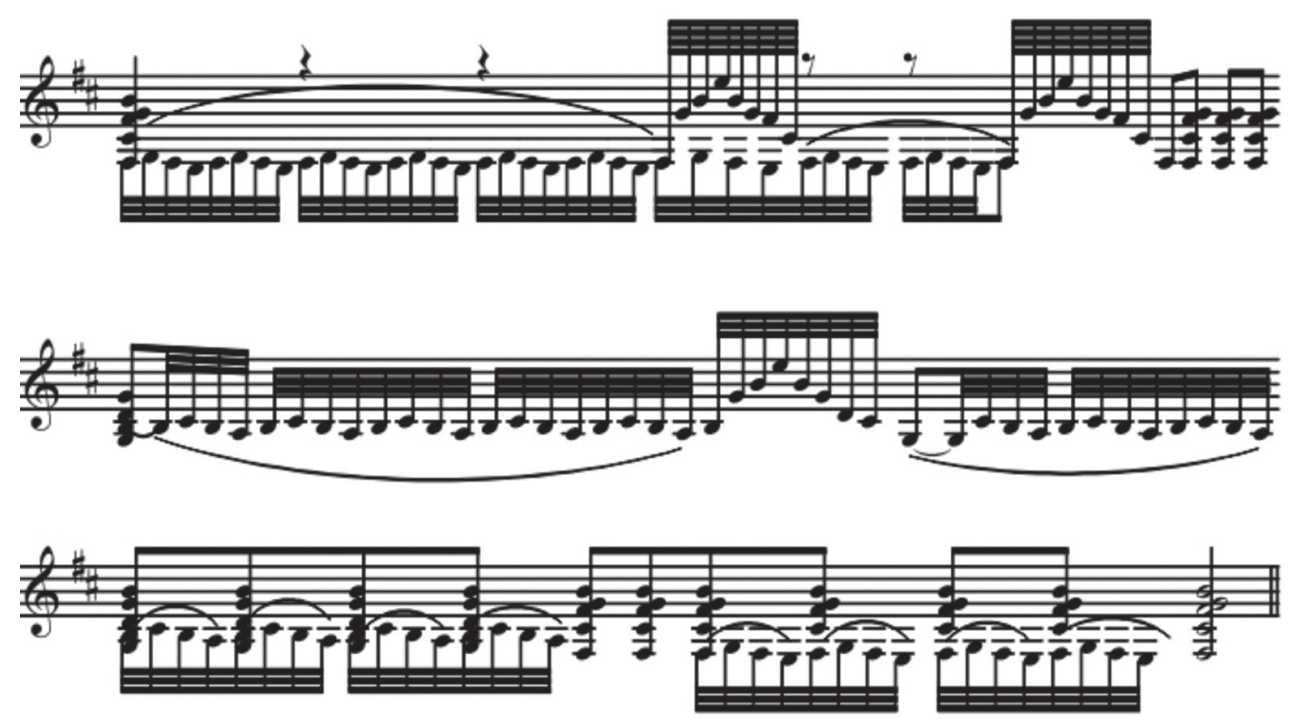

EJEMPLO 19. Ligados en Taranta. 
Este tipo de ligados representan una forma ideal para entrenar la mano izquierda ya que se adquiere gran fuerza y precisión. Puede ayudar, por ejemplo, en la realización de ornamentos en la música barroca.

Otro ejemplo con el que se desarrolla mucha velocidad en la realización de ligados, es en el siguiente fragmento de Taranta, estilo al que le es muy propio el uso del ligado rápido. Normalmente se hace el ligado con una o varias notas sostenidas, es decir, mientras unos dedos ligan, otros permanecen fijos en una posición.

También encontramos una forma interesante de ligados que intercalan sonidos no ligados. Son notas no ligadas a las notas inmediatas sino que se ligan a una tercera o cuarta nota.
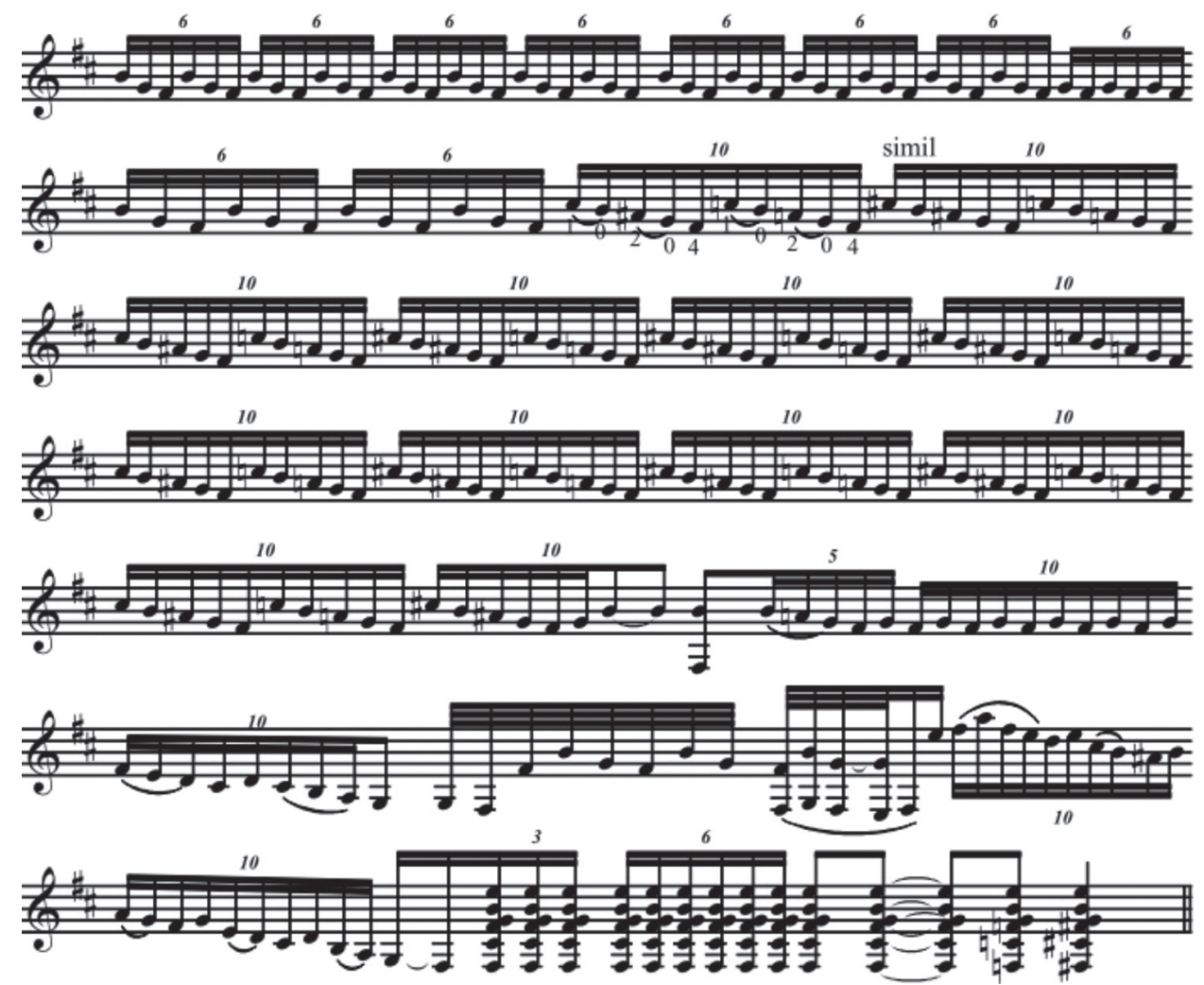

EJEMPLO 20. Ligados en Taranta.

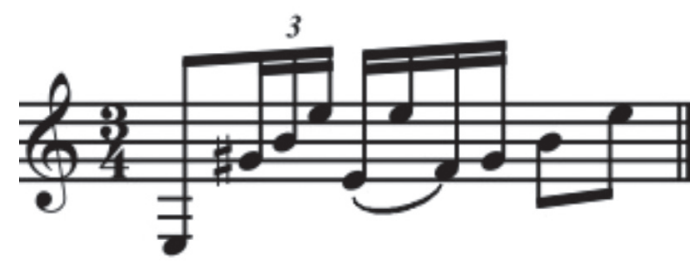

EJEMPLO 21. Ligado de notas no consecutivas. 


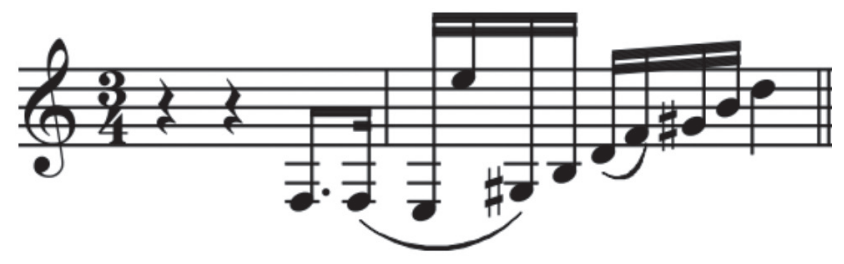

EJEMPLO 22. Ligado de notas no consecutivas.

Otra técnica muy común en el flamenco es la de producir un sonido muy parecido al ligado entre dos notas en cuerdas distintas. Evidentemente, no se pueden ligar dos notas de manera convencional en cuerdas distintas, por lo tanto, lo que se hace es que se toca la primer nota, y la segunda se hace martillada. El golpe del dedo de la mano izquierda sobre el traste, es el que produce el sonido y por lo tanto no interviene el ataque de la mano derecha.
Esto se hace en el flamenco para evitar que la mano izquierda tenga que trasladarse para ligar, ya que estos ligados se hacen de manera muy rápida y constante. Aquí apreciamos como el "la" de la cuarta cuerda se toca de manera pulsada, e inmediatamente se martilla el "sol" con el cuarto dedo en la quinta cuerda, produciéndose un efecto muy parecido al ligado.

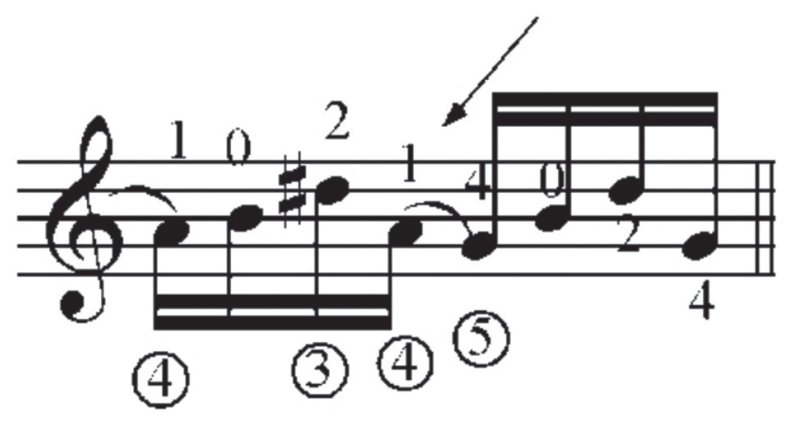

EJEMPLO 23. Ligado entre cuerdas distintas. 


\subsubsection{Movimientos del Pulgar}

Además del alzapúa, el pulgar realiza movimientos muy interesantes que los utiliza con mucha frecuencia; por ejemplo, el intercalar su ataque con el dedo índice. Se hace con un giro de muñeca, como si el giro fuera quien determinara el ataque, lográndose gran velocidad.
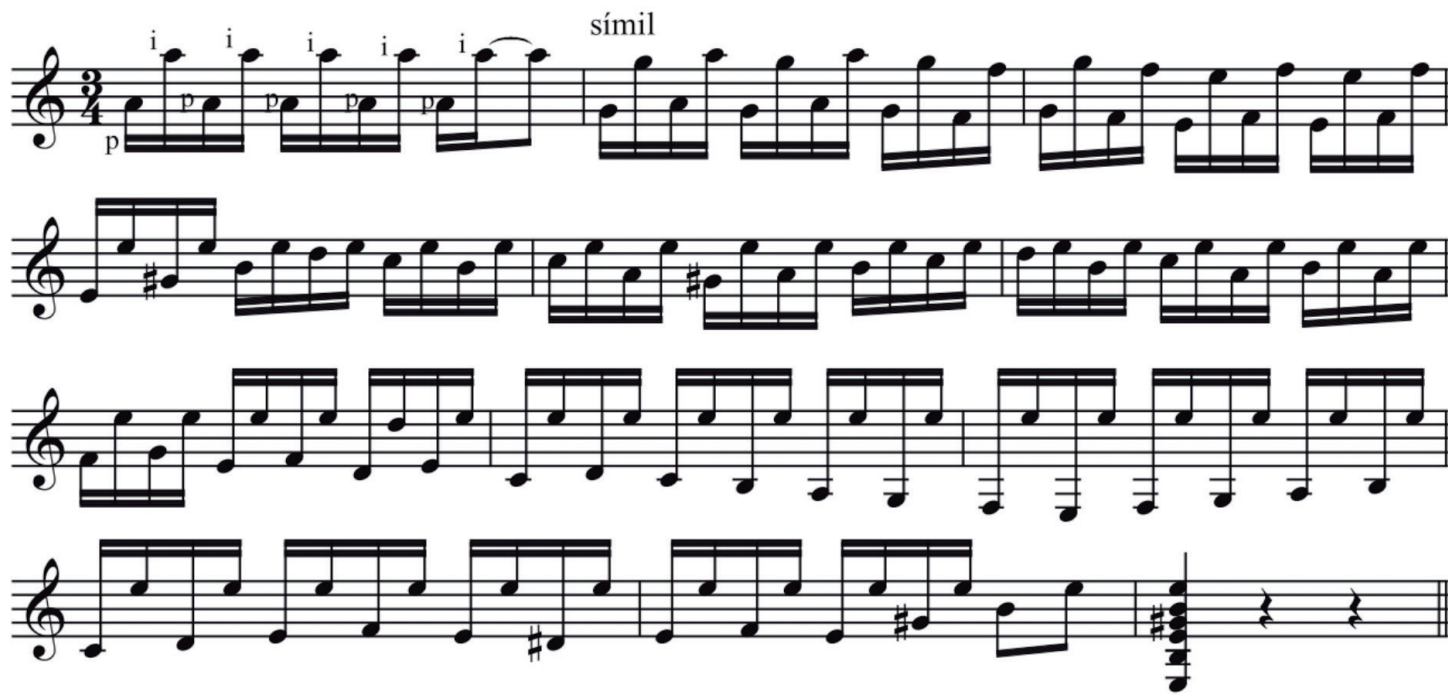

EJEMPLO 24. Pulgar-índice.

Otro ejemplo interesante es cuando el pulgar ataca la cuerda apoyando para ligar, y realiza un giro de muñeca como si en cada ataque el pulgar rebotara con la cuerda.
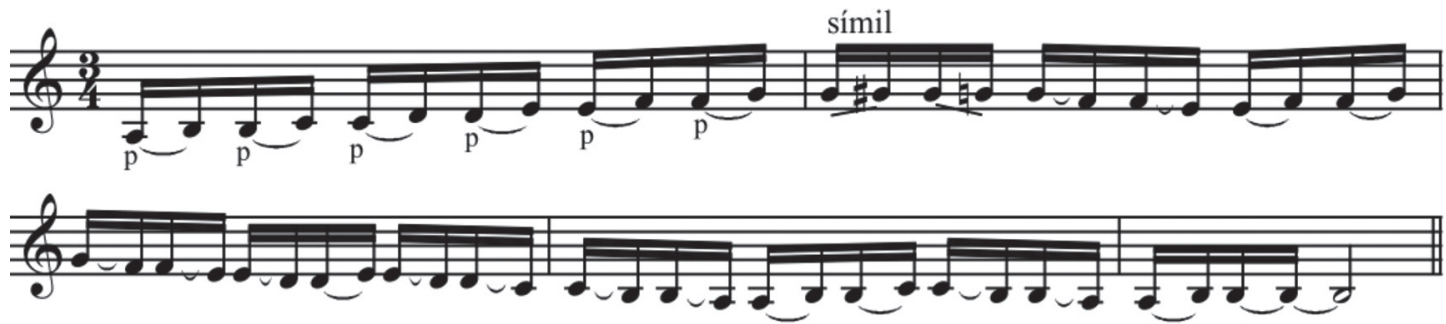


\section{Notas}

1. De canto, designa el canto flamenco. En el léxico flamenco los vocablos cante y flamenco son sinónimos.

2. $\quad$ Frase melódica o floreo que el tocaor ejecuta casi siempre punteando entre copla y copla o antes del cante. De inspiración personal el ejecutante crea una música cargada de melismas y fantasía ornamental.

3. Local donde se despachan bebidas y se ofrecen recitales de cante, baile y toque flamencos. Tuvieron su auge en la segunda mitad del siglo XIX. A través de ellos el cante logró alcanzar difusión y arraigo popular.

4. Intérprete del cante flamenco.

5. Pieza o número musical de la guitarra flamenca. Cada una de las diversas maneras de acompañar musicalmente un cante o un baile flamenco.

6. Designa las cuerdas graves. En la guitarra se refiere a las cuerdas cuarta, quinta y sexta.

\section{Bibliografía}

Álvarez Caballero, Ángel. 1993. "La guitarra flamenca". En La Guitarra en la Historia IV: 23-46.

Blas Vega, José y Manuel Ríos Ruiz. 1988. Diccionario enciclopédico Ilustrado del flamenco. Madrid: Editorial Cinterco.
1994. "Ramón Montoya: La guitarra flamenca". En La Guitarra en la Historia V: 65-92.

Córdoba, Mariano. 1971. Flamenco guitar. New York: Oak Publications.

Guyton, Arthur C. 1998. Tratado de Fisiología Médica. México: 9 Edición, Editorial McGraw-Hill Interamericana.

Leblon, Bernard. 1991. El Cante Flamenco. Madrid: Editorial Cinterco.

Marín, Rafael. 1902. Método de Guitarra por Música y Cifra. Aires Andaluces. Madrid: Sociedad de Autores Españoles.

Medina, Emilio. 1958. Método de Guitarra Flamenca. Buenos Aires: Editorial Ricordi.

Molina, Ricardo y Antonio Mairena. 1979. Mundo y formas del cante flamenco. Granada: Librería Al-Andalus.

Pérez, Mariano. 1985. Diccionario de la Música y los Músicos. Tomo II, Madrid: Ediciones Istmo.

Sánchez, Francisco. 1993. La guitarra de Paco de Lucía. Madrid: Sociedad Española de Ediciones Musicales, S.A.

Torres Cortés, Norberto. 1997. "La guitarra flamenca a principios de siglo". En La guitarra en la historia VIII: 79-121. 